\section{Autoantikörper gegen Sm}

W. Stöcker und W. Schlumberger

Euroimmun Medizinische Labordiagnostika AG, Lübeck, Deutschland

Synonym(e) Sm-Antikörper; Anti-Sm-Antikörper; Anti-Sm

Englischer Begriff anti-Sm antibodies

Definition Die Bezeichnung des Anti-Sm-Antikörpers ist abgeleitet vom Namen des Indikatorpatienten Smith. Bei den korrespondierenden Antigenen handelt es sich um eine Gruppe von 7 als Core-Proteine B/B', D1, D2, D3, E, F und $\mathrm{G}$ bezeichnete Bestandteile kleiner Ribonukleoproteine (,small nuclear ribonucleoproteins", snRNP). Der RNAAnteil wird in Abhängigkeit vom chromatografischen Verhalten als U1, U2, U4 und U5 bezeichnet und die Ribonukleoproteine entsprechend als U1-,U2-, U4- und U5-snRNP. Autoantikörper gegen Sm können gegen eines oder mehrere der Core-Proteine gerichtet sein.

Funktion - Pathophysiologie Autoantikörper gegen Sm besitzen eine hohe Spezifität für den systemischen Lupus erythematodes.

Untersuchungsmaterial Serum, Plasma.

Probenstabilität Autoantikörper sind bei $+4{ }^{\circ} \mathrm{C}$ bis zu 2 Wochen lang beständig, bei $-20^{\circ} \mathrm{C}$ über Monate und Jahre hinweg.

Analytik Autoantikörper gegen Sm zeigen im indirekten Immunfluoreszenztest (IIFT, > Immunfluoreszenz, indirekte) auf HEp-2-Zellen in der Regel eine grobgranuläre, manchmal auch eine mittel- bis feingranuläre Fluoreszenz, die über den gesamten Zellkern verteilt ist, aber die Nukleoli freilässt. In Mitosezellen sind die kondensierten Chromosomen dunkel, die Peripherie zeigt eine fast homogene, glatte Fluoreszenz. Gewebeschnitte der Primatenleber weisen ebenfalls eine granuläre Fluoreszenz auf, die Nukleoli sind ausgespart. Autoantikörper gegen U1-nRNP und Sm reagieren mit der Primatenleber ebenso stark wie mit HEp-2-Zellen, im Gegensatz zu Antikörpern gegen Ro/SS-A ( $\triangleright$ Autoantikörper gegen SS-A) und La/SS-B ( $\vee$ Autoantikörper gegen SS-B).

Bei einem positiven Resultat im IIFT kann zur genauen Identifizierung des Zielantigens ein monospezifischer $\triangleright$ Enzymimmunoassay ( $\triangleright$ Enzyme-linked Immunosorbent assay, Chemilumineszenz-Immunoassay) oder $\triangleright$ Immunblot (Linienblot) mit nativ aufgereinigten Sm-Antigenen oder ein - Western blot mit Zellkernantigenen eingesetzt werden.

Referenzbereich - Erwachsene Antikörpertiter $<1: 100$.

Referenzbereich - Kinder S. Erwachsene.

Interpretation Autoantikörper gegen Sm besitzen eine hohe Spezifität für den systemischen Lupus erythematodes. Sie sind neben $\triangleright$ Autoantikörper gegen Doppelstrang-DNA, - Autoantikörper gegen Nukleosomen und > Autoantikörper gegen ribosomale Phosphoproteine als pathognomonisch für diese Erkrankung einzustufen, kommen aber nur bei 5-40 \% der Patienten vor (Kaukasier 8 \%, Negroide $30 \%$ ).

\section{Literatur}

Tan EM, Chan EKL, Sullivan KF et al (1988) Antinuclear antibodies (ANAs): diagnostically specific immune markers and clues toward the understanding of systemic autoimmunity. Clin Immunol Immunopathol 47:121-141

Zieve GW, Khusial PR (2003) The anti-Sm immune response in autoimmunity and cell biology. Autoimmun Rev 2(5):235-240 